\title{
Effectiveness and failure factors of manual aspiration using a small needle for large pneumothorax in stable patients
}

\author{
Takahiro Homma ${ }^{1,2}$, Toshihiro Ojima ${ }^{1,2}$, Yoshifumi Shimada ${ }^{2}$, Keitaro Tanabe ${ }^{2}$, Yutaka Yamamoto ${ }^{1,2}$, \\ Yushi Akemoto $^{2}$, Naoya Kitamura ${ }^{2}$ \\ ${ }^{1}$ Division of Thoracic Surgery, Joetsu General Hospital, Niigata, Japan; ${ }^{2}$ Department of General Thoracic and Cardiovascular Surgery, Graduate \\ School of Medicine and Pharmaceutical Sciences, University of Toyama, Toyama, Japan \\ Contributions: (I) Conception and design: T Homma, T Ojima; (II) Administrative support: T Homma, T Ojima; (III) Provision of study materials or \\ patients: All authors; (IV) Collection and assembly of data: All authors; (V) Data analysis and interpretation: T Homma; (VI) Manuscript writing: All \\ authors; (VII) Final approval of manuscript: All authors. \\ Correspondence to: Takahiro Homma. Department of General Thoracic and Cardiovascular Surgery, Graduate School of Medicine and Pharmaceutical \\ Sciences, University of Toyama, 2630 Sugitani, Toyama 930-0194, Japan. Email: hommat@med.u-toyama.ac.jp.
}

\begin{abstract}
Background: Manual aspiration as the initial management of a large pneumothorax in a clinically stable patient has been reported to be safe and effective. However, the effect with smaller needles, the number of aspiration, the indication other than spontaneous pneumothorax and failure factors are unknown. We assessed the effectiveness and failure risk factors of manual aspiration up to three using a 20- or 22-gauge (G) needle in patients with a large, clinically stable pneumothorax.

Methods: We included 107 clinically stable patients with large pneumothorax. Patients who were unstable, required a ventilator, underwent chest tube drainage or had an observed small pneumothorax, bilateral pneumothorax, hemopneumothorax, or postoperative pneumothorax were excluded. Up to three aspirations were performed using 20 - or $22-\mathrm{G}$ intravenous needles. When the aspiration volume was $\geq 2,500 \mathrm{~mL}$ or lung expansion did not occur, a chest tube was placed.

Results: The first aspiration was successful in 57 patients (53.3\%), the second in 16 patients (59.3\%), and the third in eight patients (80.0\%). No patient experienced any obvious complications or required emergent hospitalization or surgery after aspiration. Aspiration failure was correlated with an inter-pleural distance $>20 \mathrm{~mm}$ at the level of the hilum [odds ratio (OR): 4.93; 95\% confidence interval (CI): 1.49-22.71; $\mathrm{P}=0.0075$ ], spontaneous secondary pneumothorax (OR: 3.11; 95\% CI: 1.14-8.76; $\mathrm{P}=0.027$ ), and $\leq 24 \mathrm{~h}$ from onset to presentation (OR: 2.95; 95\% CI: 1.12-8.26; $\mathrm{P}=0.028$ ). There were no significant differences in intrathoracic pressure after aspiration or plasma factor XIII levels between patients with resolved and persistent pneumothorax.

Conclusions: Manual aspiration up to three times using a small needle might be one of a treatment option in clinically stable patients with any large pneumothorax. Aspiration failure was correlated with an inter-pleural distance $>20 \mathrm{~mm}$ at the level of the hilum, spontaneous secondary pneumothorax, and $\leq 24 \mathrm{~h}$ from onset to presentation.
\end{abstract}

Keywords: Pneumothorax; aspiration; chest tube; plasma factor XIII; intrathoracic pressure

Submitted Oct 03, 2021. Accepted for publication Jan 14, 2022.

doi: $10.21037 /$ jtd-21-1587

View this article at: https://dx.doi.org/10.21037/jtd-21-1587

\section{Introduction}

The initial management of pneumothorax is decided based on the patient's clinical stability, pneumothorax size, and risks of recurrent pneumothorax $(1,2)$. Management guidelines for a large pneumothorax in a clinically stable patient remain controversial. Treatment options for these patients include inserting a chest tube, aspiration, thoracic vent, and surgical treatment (3). The British Thoracic 
Society (BTS) pleural disease guidelines 2010 recommend needle aspiration (1). Simple aspiration is as effective and more feasible than chest tube insertion (1-17). One of the background is the placement of a chest tube includes the risks of severe pain, intercostal vessel bleeding, intercostal nerve injury, and injury to the lung, kidney, liver, and heart (18-20). These risks are increased in patients with intrathoracic adhesions, a history of pneumothorax, and severe emphysema, depending on the physician or assistant's inexperience. Recently, there has been reported a careful follow-up for spontaneous pneumothorax (21) and effect on the ambulatory management (22). A large bore chest tube drainage and regular inpatient admission are becoming less of the primary strategies for treating primary spontaneous pneumothorax (PSP). Therefore, the current controversy centers on three competing evidence-based options for ambulatory management of large pneumothoraces: watchful waiting $(20,22,23)$ vs. 16-gaude $(G)$ needle aspiration (7-10,12-16) vs. thoracic vent with an 8-11 French tube (21,24-28). These reports indication are mainly for PSP, but other pneumothorax is well unknown. Standard aspiration needle is mainly used by $16-\mathrm{G}$, and the effect with a smaller needle and the number of aspiration times have not been fully verified. Ambulatory care with a thoracic vent tend to be widespread, but it also concerns about adverse events (22).

In 2013, we conducted a prospective, two-center study to assess the effectiveness of manual aspiration using a 20- or 22-G needle in clinically stable patients with a all type large pneumothorax due to any cause. The primary endopoint was manual aspiration success up to three using a small needle in patients with a large, clinically stable pneumothorax. The secondary goal was to assess the risk factors of manual aspiration failure. This study had some novelties: (I) the indication was independent of the degree of collapse or etiology in clinically stable patients; (II) small needles (20-22-G) were used; (III) aspiration was attempted thrice; (IV) intrathoracic pressure was measured; (V) serum plasma factor XIII was measured $(29,30)$; and (VI) the factors of manual aspiration failure was assessed.

We present the following article in accordance with the TREND statement checklist (available at https://jtd. amegroups.com/article/view/10.21037/jtd-21-1587/rc).

\section{Methods}

\section{Study design and patients}

This study was registered with the UMIN Registry (UMIN 000016004), approved by the Ethics Committee of Joetsu
General Hospital (J-79), and followed the principles of the Declaration of Helsinki (as revised in 2013). Informed consent was obtained from all patients. Patients who presented to Joetsu General Hospital (Niigata, Japan) and Toyama University Hospital (Toyama, Japan) with a pneumothorax between July 2013 and June 2018 were included.

Pneumothorax size was determined by the distance from the lung apex rim to the ipsilateral thoracic cupola and the distance from the horizontal rim to the ipsilateral chest wall at the level of the hilum on a standard upright chest radiograph. A large pneumothorax was basically defined as $\geq 3 \mathrm{~cm}$ from the apex to the cupola following the ACCP guideline. When the decision was difficult due to intrathoracic adhesions, the size was determined as the presence of a visible rim of $>2 \mathrm{~cm}$ between the lung margin and chest wall at the level of the hilum following the BTS guideline (1). Clinically stable patients with a large pneumothorax were presented with the options of a chest tube, aspiration, or surgery, and the advantages and disadvantages of each treatment method were discussed. The patients selected the indicated treatment option. Patients who were unstable, required a ventilator, underwent chest tube drainage or had a small pneumothorax, bilateral pneumothorax, hemopneumothorax, or postoperative pneumothorax were excluded from the study. Patients who desired chest tube placement or those with psychiatric disorders that made it difficult for the patient to participate were also excluded. All types of pneumothorax were eligible for aspiration, except those that occurred after thoracic surgery. Patients were indicated regardless of whether the first or the recurrence.

\section{Aspiration procedure}

The aspiration protocol is shown in Figure 1. Manual aspiration was performed in an outpatient or emergency room setting. Patients were placed in the decubitus position with the diseased side up or in the supine position if the decubitus position resulted in worse pain or dyspnea. Chest ultrasonography was performed to confirm intrathoracic adhesions and the distance from the skin to the pleural space at the puncture site $(31,32)$. The size of the intravenous needle was chosen according to the depth of the intrathoracic space. A 20- or 22-G needle (Supercath 5, MEDIKIT Co., Ltd., Tokyo, Japan) was used. After skin disinfection, field preparation, and administration of local anesthesia (1\% lidocaine), a small-calibre intravenous 


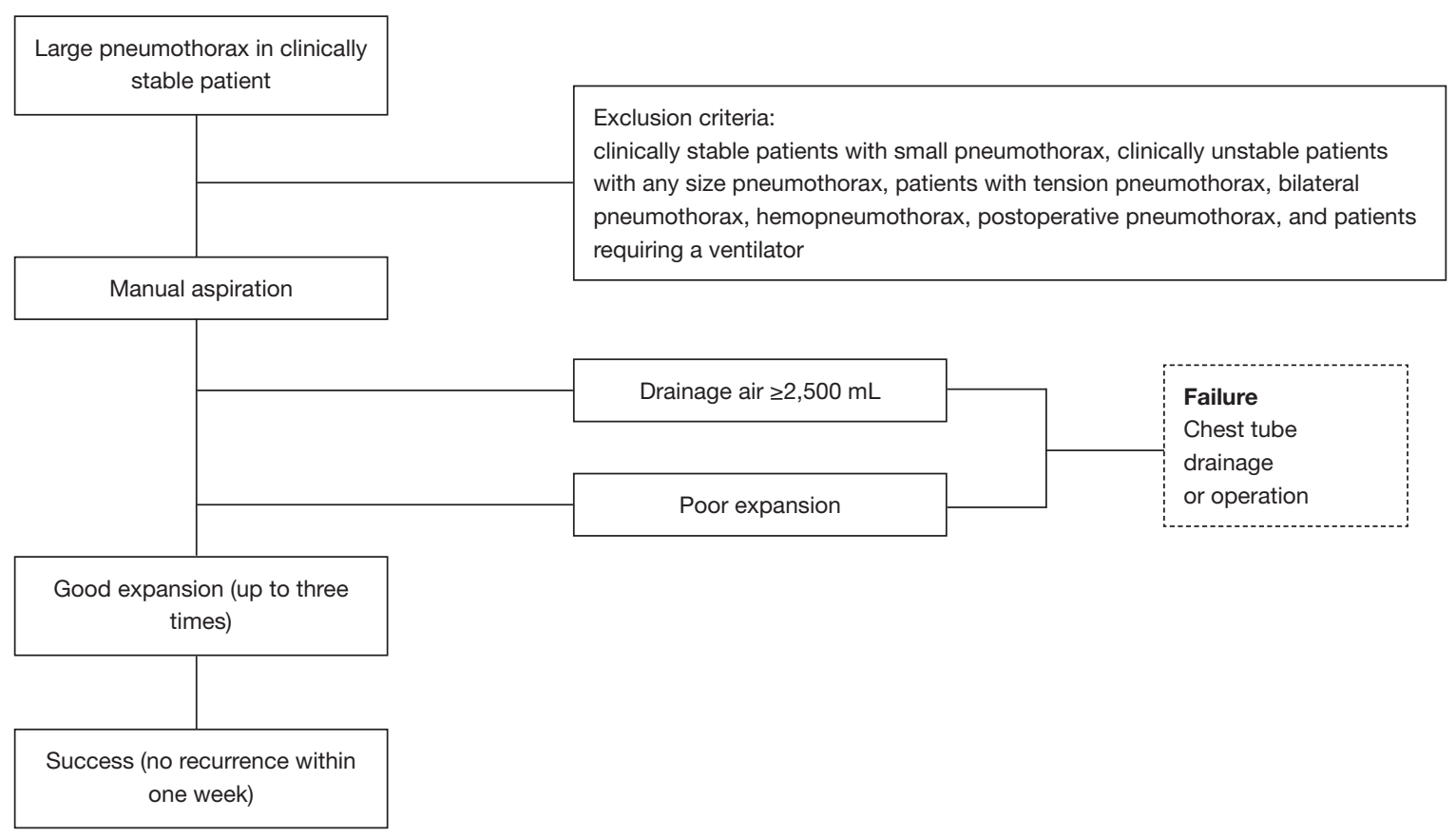

Figure 1 Treatment flowchart. Patients with all types of pneumothorax were eligible for aspiration, except for patients recovering from thoracic surgery. If lung expansion was complete or only a small amount of apical air was present, the patient was discharged. If the lung expansion was insufficient, a second aspiration was immediately attempted. Manual aspiration was attempted up to three times. If sufficient lung expansion was not attained after three aspiration attempts, the patient underwent chest tube drainage or surgery.

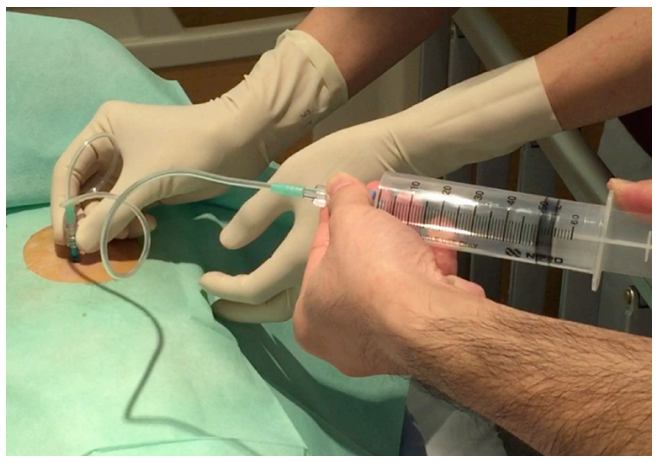

Figure 2 Manual aspiration. A small-caliber intravenous needle catheter was introduced after skin disinfection, field preparation, and local anesthesia. The catheter was connected to a $50-\mathrm{mL}$ syringe. Air was manually and gradually aspirated to the point of resistance.

needle catheter was introduced. After advancing to a depth where the catheter could be fully inserted into the pleural space, the metal needle was pulled out. The puncture site was in the fifth or sixth intercostal space at the midaxillary line in the decubitus position or in the second or third intercostal space at the midclavicular line in the supine position. The site with the shortest depth was chosen first. After the needle had entered the pleural space, confirmed by air bubbling in the lidocaine-filled syringe, the catheter was advanced into the pleural space. The catheter was connected to a $50-\mathrm{mL}$ syringe via a three-way valve (Figure 2). Air was manually and gradually aspirated to the point of resistance. The catheter was immediately withdrawn, and chest radiography was performed. If lung expansion was complete or only small apical pneumothorax was present, the patient was discharged soon. If the amount of air was $\geq 2,500 \mathrm{~mL}$, a chest tube was placed. The policy of chest tube insertion with $2,500 \mathrm{~mL}$ or more complied with the BTS guidelines (1). If the lung expansion was insufficient, an additional aspiration was immediately attempted after chest ultrasonography on the same day. A chest X-ray was repeated and patients were discharged, even if the lung expansion was insufficient. If careful observation was desirable for a patient, a patient was admitted to the hospital. Consecutive aspirations performed on the same day were counted as one.

Patients were told to return the day after discharge 


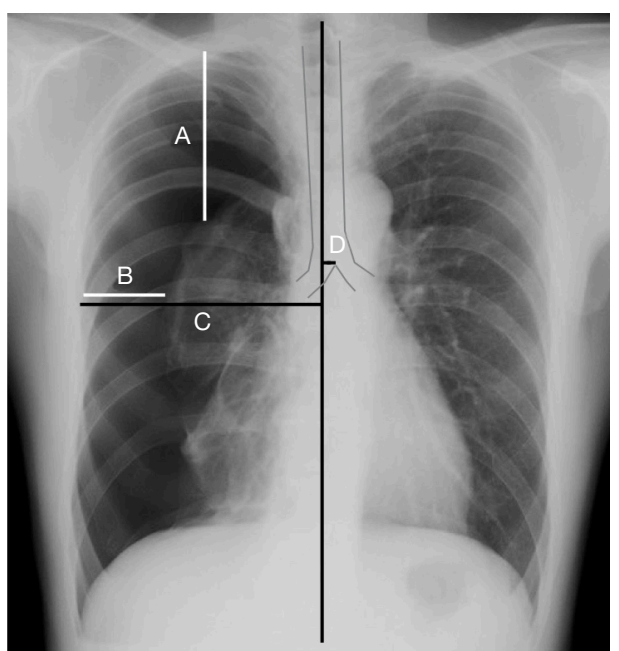

Figure 3 Chest X-ray findings and assessments. (A) The distance from the lung apex rim to the ipsilateral thoracic cupola in the midclavicular line. (B) The inter-pleural distance, and (C) represents the inner hemithorax distance at the level of the hilum. (D) The distance from the midline to the carina at the level of the carina.

for a subsequent chest $\mathrm{X}$-ray. If the lung expansion was poor, manual aspiration was performed again and verified via chest radiography. Patients were followed until lung expansion was complete, and manual aspiration was attempted up to three times. If sufficient lung expansion was not attained after three aspiration attempts, the patient underwent chest tube drainage or surgery.

\section{Variables and assessments}

The primary endopoint was manual aspiration success up to three using a 20 - or $22-\mathrm{G}$ needle in patients with a large, clinically stable pneumothorax. The secondary goal was to assess the risk factors of manual aspiration failure.

Aspiration success was defined as complete lung expansion or only a small rim of apical pneumothorax without recurrence within 1 week. Aspiration failure was defined as $\geq 2,500 \mathrm{~mL}$ of aspirated air, aspiration more than three times, and the requirement of a chest tube or surgery. We recorded the patients' age, sex, smoking history, pneumothorax diagnosis [PSP, secondary spontaneous pneumothorax (SSP), traumatic pneumothorax, or iatrogenic pneumothorax], affected side, time from onset to presentation, chest $\mathrm{X}$-ray findings [degree of the collapsed lung (slight, medium, or severe), pneumothorax size, distance from the lung apex rim to the ipsilateral thoracic cupola in the midclavicular line, interpleural distance, inner hemithorax distance at the level of the hilum, distance from the midline to the carina at the level of the carina] (Figure 3), number of aspirations, amount of air in the aspiration drainage, complications, emergent hospitalization, emergent operations after aspiration, serum plasma factor XIII, and intrathoracic pressure on inspiration and expiration after aspiration.

The diagnosis of pneumothorax type followed the ACCP guidelines (33). Performing a reassessment of the aspiration the next day followed the guidelines of previous reports (4). The time from onset to presentation was determined via a detailed patient interview. The median line of the chest $\mathrm{X}$-ray was defined as the line connecting the midpoint of both sternoclavicular joints and the spinous process. Pneumothorax size was determined using the ACCP and BTS guidelines (1,33), the Light index (34,35), and the Japan Society for Pneumothorax and Cystic Lung Diseases (JSPCLD) classifications on chest X-rays. Using JSPCLD classifications, the pneumothoraces were divided into three categories: mild (apex of the collapsed lung was above the clavicle), moderate (apex was below the clavicle, the lung was not almost completely collapsed), and severe (lung was almost completely collapsed). The intrathoracic pressure was measured for $10 \mathrm{~s}$ using a manometer (FUSO-8230, FUSO, Co, Ltd., Tokyo, Japan) connected to the catheter. The maximum intrathoracic pressure measured during the 10 -s period was used in this study.

\section{Statistical analyses}

Our preplanned sample size was a total of 100 consecutive patients full filled the inclusion and exclusion criteria in the two study sites. They were evaluated prospectively for various effective factors of manual aspiration using a 20or 22-G needle in clinically stable patients with a large pneumothorax due to any cause.

The differences between groups were evaluated using a non-parametric Wilcoxon rank-sum test. The chi-squared test or Fisher's exact test was used to compare categorical variables as appropriate. All reported $\mathrm{P}$ values are two-sided.

The risk factors included in the multivariate analyses were selected based on the univariate analyses, statistical independence, and clinical significance. Multivariate logistic regression was used to identify independent risk factors of aspiration failure. A nominal logistic regression was initially performed with preoperative and intraoperative variables 


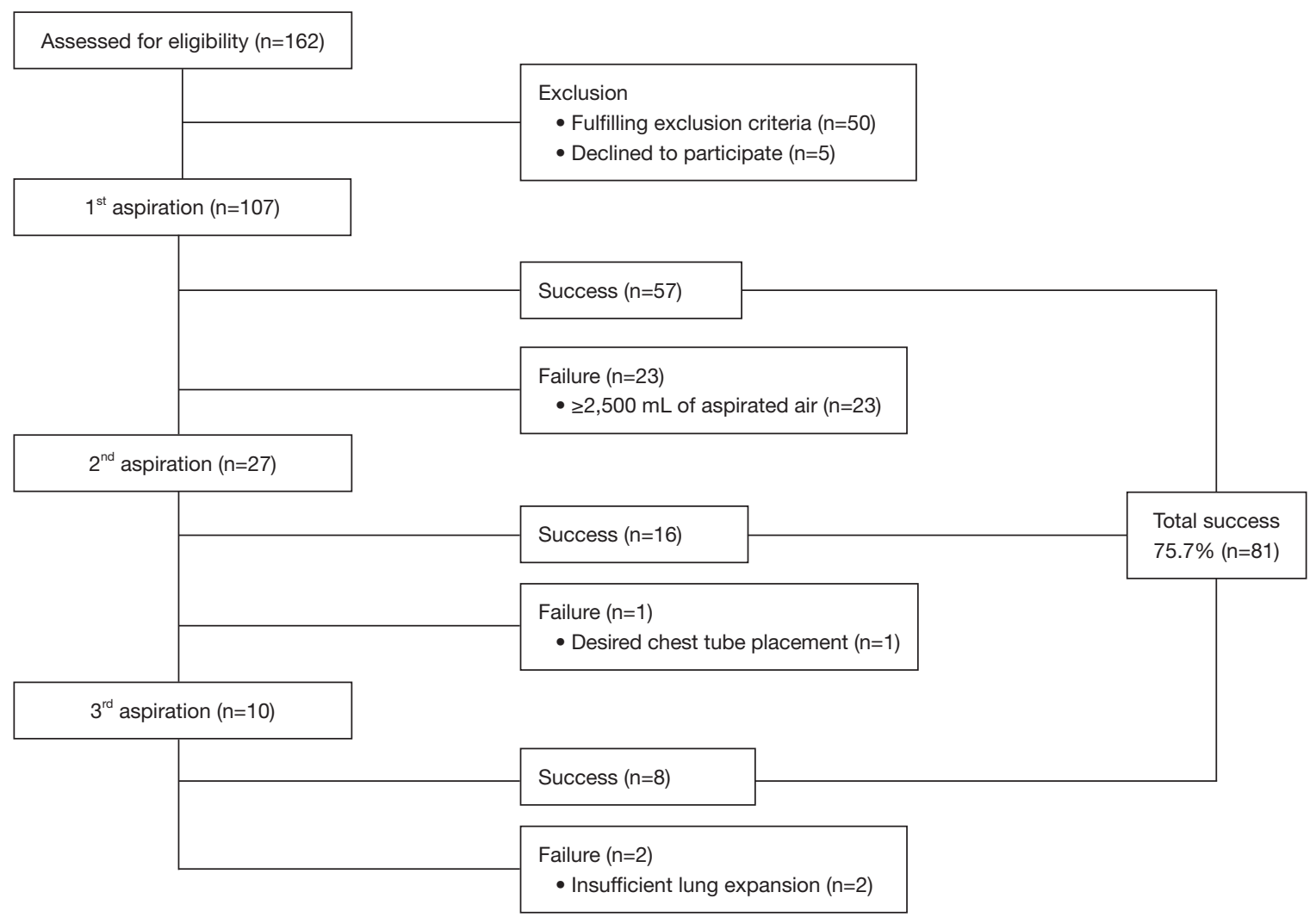

Figure 4 Follow diagram of the study. Aspiration failure is defined as 2,500 $\mathrm{mL}$ of aspirated air, aspiration more than three times, or the requirement of a chest tube or surgery. The success rate of the first aspiration was $53.3 \%(57 / 107)$ of the second aspiration was $59.3 \%$ (16/27), and of the third aspiration was $80.0 \%(8 / 10)$. A total of 81 patients $(75.7 \%)$ were successfully treated with manual aspiration.

that were significant univariate predictors of the outcome being modelled. Due to the rarity of the outcome events being modelled, variables with $\mathrm{P}<0.1$ were included in the multivariate logistic regression models. The cut-off value for inter-pleural distance at the level of the hilum was $20 \mathrm{~mm}$ based on the BTS guidelines. The cut-off value for midline shift distance at the level of the carina was $10 \mathrm{~mm}$ based on the results of a preliminary receiver characteristics analysis, which showed $9 \mathrm{~mm}$ to be the optimal cut-off value with a C-index of 0.39. All statistical analyses were performed using JMP version 12.0 statistical software (SAS Institute, Inc., Cary, NC, USA). Statistical significance was set at $\mathrm{P}<0.05$.

\section{Results}

Overall, 162 patients were eligible for this study, and 107 were enrolled (Figure 4). The patients' characteristics are summarized (Table 1). Follow-up within 1 week was achieved in all patients. No patient experienced any complications after aspirations or withdrew from the study.

Of the 107 patients, 91 (85.0\%) were male. The median patient age was 36 years, and 59 patients $(55.1 \%)$ had a left pneumothorax. The most common type of pneumothorax was PSP $(68 / 107 ; 63.6 \%)$, followed by SSP $(31 / 107$; $28.9 \%)$, traumatic $(5 / 107 ; 4.7 \%)$, and iatrogenic $(3 / 107$; $2.8 \%)$. Forty-eight patients $(44.9 \%)$ sought medical assistance within $24 \mathrm{~h}$ of the injury. The success rate of the first aspiration was $53.3 \%(57 / 107)$, the second aspiration was $59.2 \%(16 / 27)$, and the third aspiration was $80.0 \%$ (8/10). Up to three aspirations, a total of 81 patients (75.7\%) were treated successfully by manual aspiration. Manual aspiration with no hospitalization was successful in patients even with severe pneumothorax, traumatic pneumothorax, or pregnant patients. No patients who failed manual aspiration required emergent surgery, though all 26 patients underwent elective surgery at a later date, including 20 
Table 1 Background of all patients

\begin{tabular}{|c|c|c|c|c|c|}
\hline Variables & $\begin{array}{l}\text { Spontaneous primary, } \\
\qquad \mathrm{n}=68(63.6 \%)\end{array}$ & $\begin{array}{c}\text { Spontaneous } \\
\text { secondary, } \mathrm{n}=31 \\
(28.9 \%)\end{array}$ & $\begin{array}{l}\text { Traumatic, } \mathrm{n}=5 \\
(4.7 \%)\end{array}$ & $\begin{array}{l}\text { latrogenic, } \mathrm{n}=3 \\
(2.8 \%)\end{array}$ & Total, n=107 (\%) \\
\hline Sex (male, \%) & $57(83.8)$ & $28(90.3)$ & $4(80.0)$ & $2(66.7)$ & $91(85.0)$ \\
\hline Smoking history (\%) & $11(16.2)$ & $30(96.8)$ & $2(40.0)$ & $3(100.0)$ & $46(42.9)$ \\
\hline \multicolumn{6}{|l|}{ Time from onset to presentation (\%) } \\
\hline$\leq 24 \mathrm{~h}$ & $32(47.1)$ & $12(38.7)$ & $3(60.0)$ & $1(33.3)$ & $48(44.9)$ \\
\hline$>24 \mathrm{~h}$ & $36(52.9)$ & $19(61.3)$ & $2(40.0)$ & $2(66.7)$ & $59(55.1)$ \\
\hline $\begin{array}{l}\text { Inter pleural distance at level of } \\
\text { the hilum (median, IQR) (mm) }\end{array}$ & 29 [17-47] & 33 [20-53] & 34 [23-34] & $16[0-19]$ & 30 [17-47] \\
\hline $\begin{array}{l}\text { Inner hemithorax distance at level } \\
\text { of the hilum (median, IQR) (mm) }\end{array}$ & $139[131-144]$ & $144[134-156]$ & 138 [127-153] & $139[133-147]$ & $139[132-146]$ \\
\hline $\begin{array}{l}\text { Midline shift distance at level of } \\
\text { the carina (median, IQR) }(\mathrm{mm})\end{array}$ & $7[0-9]$ & $7[3-10]$ & 9 [0-13] & $0[0-3]$ & $6[0-9]$ \\
\hline $\begin{array}{l}\text { Pneumothorax size using the Light } \\
\text { index (median, IQR) (\%) }\end{array}$ & $52.9(33.2-72.4)$ & $53.9(34.3-74.0)$ & $50.2(41.9-58.9)$ & $29.2(0-35.7)$ & $51.7(34.1-72.3)$ \\
\hline \multicolumn{6}{|l|}{ JSPCLD classification criteria (\%) } \\
\hline After aspiration & $-6.5(-8.8$ to -4.5$)$ & $-1.4(-6.9$ to +3.0$)$ & $-6.0(-8.5$ to -4.3$)$ & $-6.0(-6.5$ to -5.0$)$ & $-6.4(-8.3$ to -4.3$)$ \\
\hline Plasma factor XIII (median, IQR) (\%) & 78 [70-91] & 108 [90-122] & 115 [91-125] & 88 [67-91] & 81 [73-109] \\
\hline $\begin{array}{l}\text { Amount of drainage air (median, } \\
\text { IQR) }(m L)\end{array}$ & $1,315[725-1,845]$ & $1,250[720-1,530]$ & $1,180[645-1,435]$ & $430[250-550]$ & $1,230[700-1,680]$ \\
\hline Aspiration success (\%) & $54(79.4)$ & $19(61.3)$ & $5(100.0)$ & $3(100.0)$ & $81(75.7)$ \\
\hline
\end{tabular}

Categorical variables are presented as $\mathrm{n}(\%)$. Continuous variables are presented as indicated. IQR, interquartile range; JSPCLD, The Japan Society for Pneumothorax and Cystic Lung Diseases

patients who underwent bullectomy, 5 who underwent covering, and 1 who underwent looping. No patient experienced any complications due to aspiration.

Older age $(\mathrm{P}=0.012)$, SSP $(\mathrm{P}=0.045), \leq 24 \mathrm{~h}$ between onset and presentation ( $\mathrm{P}=0.041)$, severe collapsed lung using the JSPCLD classification system $(\mathrm{P}=0.0028)$, inter- pleural distance $>20 \mathrm{~mm}$ at the level of the hilum $(\mathrm{P}=0.0082)$, severe pneumothorax using the Light index $(\mathrm{P}<0.001)$, $\geq 10 \mathrm{~mm}$ midline shift distance at the level of the carina $(\mathrm{P}<0.001)$, and high intrathoracic pressure before aspiration $(\mathrm{P}=0.0051)$ were found to be significant risk factors for aspiration failure (Table 2). There were no significant 
Table 2 Univariate analysis of patients with aspiration failure

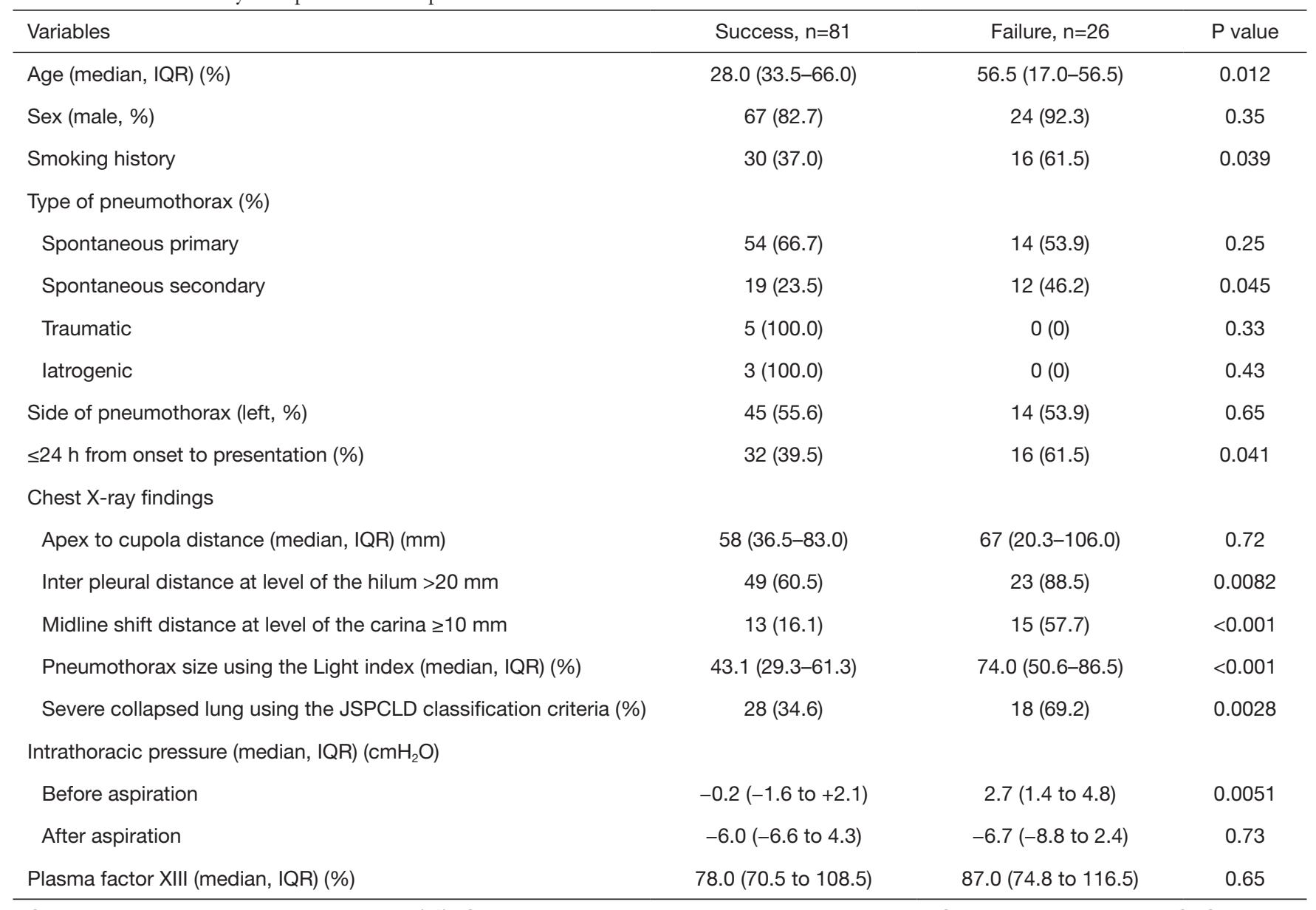

Categorical variables are presented as $\mathrm{n}(\%)$. Continuous variables are presented as indicated. IQR, interquartile range; JSPCLD, The Japan Society for Pneumothorax and Cystic Lung Diseases.

differences in sex, PSP, traumatic pneumothorax, iatrogenic pneumothorax, diseased side, apex to cupola distance, intrathoracic pressure after aspiration, or plasma factor XIII among the patients with resolved and those with persistent pneumothorax.

An inter-pleural distance of $>20 \mathrm{~mm}$ at the level of the hilum [odds ratio (OR): 4.93; 95\% confidence interval (CI): 1.49-22.71; P=0.0075], SSP (OR: 3.11; 95\% CI: 1.148.76; $\mathrm{P}=0.027)$, and $\leq 24 \mathrm{~h}$ between onset and presentation (OR: 2.95; 95\% CI: $1.12-8.26$; $\mathrm{P}=0.028$ ) were found to be independently associated with aspiration failure (Table 3). An inter-pleural distance $>20 \mathrm{~mm}$ at the level of the hilum was significantly associated with severe collapsed lung using JSPCLD classification $(\mathrm{P}=0.0002)$, severe pneumothorax using the Light index $(\mathrm{P}<0.0001), \geq 10 \mathrm{~mm}$ midline shift at the level of the carina $(\mathrm{P}=0.0044)$, and higher intrathoracic pressure before aspiration $(\mathrm{P}=0.0054)$. SSP was also associated with age $(\mathrm{P}<0.0001)$.

\section{Discussion}

This study was a prospective, two-center study assessing the effectiveness of manual aspiration with a 20 - or 22-G needle in clinically stable patients with a large pneumothorax due to any cause. In this study, $75.7 \%$ of patients were successfully treated with manual aspiration and did not require hospitalization. Aspiration failure was correlated with an inter-pleural distance $>20 \mathrm{~mm}$ at the level of the hilum (OR: 4.93; 95\% CI: 1.49-22.71; $\mathrm{P}=0.0075$ ), spontaneous secondary pneumothorax (OR: $3.11 ; 95 \% \mathrm{CI}$ : 1.14-8.76; $\mathrm{P}=0.027)$, and $\leq 24 \mathrm{~h}$ from onset to presentation (OR: 2.95; 95\% CI: 1.12-8.26; $\mathrm{P}=0.028$ ). There were 
Table 3 Multivariate logistic regression analysis of patients with aspiration failure

\begin{tabular}{|c|c|c|c|}
\hline Variables & OR & $95 \% \mathrm{Cl}$ & $P$ value \\
\hline Inter pleural distance at level of the hilum $>20 \mathrm{~mm}$ & 4.93 & $1.49-22.71$ & 0.0075 \\
\hline \multicolumn{4}{|l|}{ Type of pneumothorax } \\
\hline Spontaneous secondary & 3.11 & $1.14-8.76$ & 0.027 \\
\hline$\leq 24 \mathrm{~h}$ & 2.95 & $1.12-8.26$ & 0.028 \\
\hline
\end{tabular}

OR, odds ratio; $\mathrm{Cl}$, confidence interval.

no significant differences in intrathoracic pressure after aspiration or plasma factor XIII between patients with resolved and persistent pneumothoraces.

Pneumothorax is a common disease (36-40). Despite the incidence of pneumothorax (38-40), several methods for initial treatment exist. Placement of a chest tube is common in the nations following the ACCP guidelines, while aspiration is recommended by the BTS. Although a careful follow-up or effect on the thoracic vent management for spontaneous pneumothorax, there are concerns about adverse events $(21,22)$. Thoracic vent had serious adverse events and similar pain compared to the standard care (22). It is also easy to imagine a sense of discomfort when a patient is inserted a foreign body such as a thoracic vent. Manual aspiration had fewer complications and could be easily performed anywhere. Achieving a resolution of pneumothorax in an outpatient setting avoids hospitalization (17) and reduces the physical, mental, and economic burden on the patient. Some patients included severe pneumothorax, iatrogenic, or pregnant women. Despite a small sample size, aspiration may be a more preferred option in all pneumothoraxes. The high success rate of aspiration $(75.7 \%)$ in this study was thought to be because of the policy that allowed up to three attempts. This was comparable to previous reports success rates ( $47.8 \%$ to $91.3 \%)$ using $16-\mathrm{G}$ needle $(7-10,12-16)$. In this study, all patients treated with aspiration had improved symptoms, even when the aspiration failed. Despite a small sample size, both traumatic and iatrogenic pneumothorax had a $100 \%$ cure rate. This was also comparable to previous reports (23). Therefore, especially for patients with iatrogenic pneumothorax, the less-invasive aspiration may be a more preferred option than chest tube placement or surgery. Aspiration with a smaller needle may serve as a lifesaving procedure that can be done by a non-specialist.
We found that an inter-pleural distance $>20 \mathrm{~mm}$ at the level of the hilum, SSP, and $\leq 24 \mathrm{~h}$ between onset and presentation are significantly associated with aspiration failure. The BTS included an inter-pleural distance $>20 \mathrm{~mm}$ at the level of the hilum and SSP when creating the algorithms to develop their guidelines. However, most patients with these conditions were successfully cured by manual aspiration in this study. Manual aspiration was preferred by patients for several reasons, including avoiding the difficult chest tube placement procedure and the subsequent requirement of antithrombotic medications. Therefore, manual aspiration should be the first choice for the initial treatment of any pneumothorax, even in patients with a risk factor for aspiration failure.

The time from pneumothorax onset to presentation also affected the success of manual aspiration. Typically, patients with pneumothorax, especially those with PSP, present several days after the onset of symptoms (41). Pulmonary fistulas may close naturally in approximately 1-3 days (42). Generally, the clinical symptoms associated with SSP are more severe than those associated with PSP (43). Therefore, clinical manifestations are unreliable indicators of pneumothorax size (44). Additionally, plasma factor XIII has been reported to be a fistula-healing factor and intraoperative bleeding $(29,30,45,46)$. In lung disease, there are some reports related to therapeutic effect of pneumothorax and prolonged air leak after pulmonary lobectomy $(47,48)$. However, effect of plasma factor XIII is controversial (49). At least, plasma factor XIII was not found to be associated with the success of manual aspiration in this study, although it cannot be ruled out that it is associated with the development of pneumothorax.

Tension pneumothorax is known that intrathoracic cavity pressure tend to be positive and affects hemodynamics $(50,51)$. Although tension pneumothorax was excluded 
from this study, we assumed that persistent air leaks cases were higher intrathoracic pressure. There may be a causal relationship between the degree of collapse and intrathoracic pressure, but at least in this study there was no statistical result as a failure factor.

The diagnosis of pneumothorax is usually confirmed via imaging, which may also yield information about the size of the pneumothorax. A standard erect chest X-ray during inspiration is recommended for the initial diagnosis of pneumothorax. Various formulae for measuring the size of pneumothorax have been reported $(34,35)$. In this study, the Light criteria, mediastinal shift, chest X-ray findings, and intrathoracic pressure were all correlated to the horizontal collapse distance. Besides the BTS included an inter-pleural distance $>20 \mathrm{~mm}$ at the level of the hilum, the horizontal collapse distance would be the most useful factor that it can be easily implemented by anyone and anywhere. Vertical collapse is widely known as the degree of collapse; however, patients with pneumothorax often have adhesions in the apical lung, rendering measurements of vertical collapse difficult. Therefore, the horizontal collapse distance was used in this study.

Chest tube insertion is complicated by the presence of adhesions, which are likely if the lung apex does not collapse $(18,19)$. As adhesions are difficult to detect on chest radiography, and computed tomography is not always available, chest ultrasonography is the most effective imaging technique to detect intrathoracic adhesions (31) and can also be used to diagnose pneumothorax (32).

The appropriate chest tube diameter for pneumothorax has been previously reported $(20,52)$. The ACCP guidelines recommend a larger bore (35-37,41-44) French chest tube, while the 2010 BTS pleural disease guidelines recommend simple aspiration using a $14-16-G$ needle. There is also a report using an 18-G needle (11). A large caliber tube is not necessary for only air drainage. Treatment time with small bore catheter was shorter than conventional chest tube drainage (53). Smaller-calibre tubes or needles have a slower flow rate. The flow rate of the $20-\mathrm{G}$ needle is $55 \mathrm{~mL} / \mathrm{min}$ and that of the $22-\mathrm{G}$ needle is $31 \mathrm{~mL} / \mathrm{min}$. Slower drainage may help prevent re-expansion pulmonary edema (54). For patients at risk of pulmonary edema, we prophylactically administered methylprednisolone sodium succinate (40 mg) $30 \mathrm{~min}$ before aspiration (55). Proper needle selection is important, especially in patients with a thick thorax. Smaller needles are also shorter. Ultrasound can also be used to determine the shortest path to the pneumothorax, which is dependent on body position.
The Supercath 5 apparatus included a built-in check valve and inner needle retraction into the safety cover with one button press, which helped minimize the risk of worsening a pneumothorax and accidental needle sticks for medical staff. A needle's characteristics must be considered when performing manual aspiration.

Initial treatment for pneumothorax should safely and effectively drain the air in the chest cavity. Ideally, this treatment should be available in any healthcare setting and be inexpensive. However, drainage via a larger bore chest tube typically requires hospitalization and may lead to complications, especially in patients with adhesions. Management of a thoracic vent and narrow bore chest tubes do not always require hospitalization, and have an economical benefit or shorter treatment time (26). However, there remains a sense of discomfort that foreign matter is indwelling, despite less pain compared to chest tube drainage $(7,15)$. The number of aspiration was reported up to the second time (7), but this time it was performed up to three times. Aspiration up to three times is an effective and safe procedure in patients with large pneumothorax, and aspiration may serve as a life-saving procedure that can be done by a non-specialist. In this study, all patients treated with aspiration had improved symptoms, even when the aspiration failed. This aspiration technique would need to learn for all physicians and medical students.

\section{Limitations}

This study has some limitations. This two-center study had a small sample size and limited ethnic diversity. A large multicenter and international study would be needed. However, the study population is prospective and sequential. This study is not a comparative study with chest tube drainage or thoracic vent. However, the effectiveness was equal to or better than previous studies. The definition of aspiration success might be too short. However, we referred to that past report (9). Even if it is cured by chest tube insertion, it is the same in conservative treatment. The significance of aspiration cures without hospitalization is even greater. The short treatment period was similar to the previous reports $(15,17)$. The time from onset to presentation was calculated with details obtained during patient interviews and was not verified in this study. However, the patient's symptoms are useful in determining if $>24$ h between onset and presentation has passed. In this study, the maximum intrathoracic pressure obtained during a 10-s measurement period was used as 
the pressure fluctuates with breathing. Very few studies regarding pneumothorax and intrathoracic pressure measurements have been reported; therefore, continuous data accumulation may be required.

\section{Conclusions}

Manual aspiration up to three times using a small needle might be one of a treatment option in clinically stable patients with any large pneumothorax. Aspiration failure was correlated with an inter-pleural distance $>20 \mathrm{~mm}$ at the level of the hilum, spontaneous secondary pneumothorax, and $\leq 24 \mathrm{~h}$ from onset to presentation.

\section{Acknowledgments}

This study was accepted at the $28^{\text {th }}$ European Conference on General Thoracic Surgery hosted by the European Society of Thoracic Surgeon in Hague, The Netherlands in 2020 (accepted abstract number 269). We would like to thank Editage (www.editage.com) for English language editing.

Funding: None.

\section{Footnote}

Reporting Checklist: The authors have completed the TREND reporting checklist. Available at https://jtd. amegroups.com/article/view/10.21037/jtd-21-1587/rc

Data Sharing Statement: Available at https://jtd.amegroups. com/article/view/10.21037/jtd-21-1587/dss

Peer Review File: Available at https://jtd.amegroups.com/ article/view/10.21037/jtd-21-1587/prf

Conflicts of Interest: All authors have completed the ICMJE uniform disclosure form (available at https://jtd.amegroups. com/article/view/10.21037/jtd-21-1587/coif). The authors have no conflicts of interest to declare.

Ethical Statement: The authors are accountable for all aspects of the work in ensuring that questions related to the accuracy or integrity of any part of the work are appropriately investigated and resolved. This study was registered with the UMIN Registry (UMIN 000016004), approved by the Ethics Committee of Joetsu General Hospital (J-79), and followed the principles of the
Declaration of Helsinki (as revised in 2013). Informed consent was obtained from all patients.

Open Access Statement: This is an Open Access article distributed in accordance with the Creative Commons Attribution-NonCommercial-NoDerivs 4.0 International License (CC BY-NC-ND 4.0), which permits the noncommercial replication and distribution of the article with the strict proviso that no changes or edits are made and the original work is properly cited (including links to both the formal publication through the relevant DOI and the license). See: https://creativecommons.org/licenses/by-nc-nd/4.0/.

\section{References}

1. MacDuff A, Arnold A, Harvey J, et al. Management of spontaneous pneumothorax: British Thoracic Society Pleural Disease Guideline 2010. Thorax 2010;65 Suppl 2:ii18-31.

2. Homma T, Sugiyama S, Kotoh K, et al. Early surgery for treatment of spontaneous hemopneumothorax. Scand J Surg 2009;98:160-3.

3. Olesen WH, Katballe N, Sindby JE, et al. Surgical treatment versus conventional chest tube drainage in primary spontaneous pneumothorax: a randomized controlled trial. Eur J Cardiothorac Surg 2018;54:113-21.

4. Noppen M, Alexander P, Driesen P, et al. Manual aspiration versus chest tube drainage in first episodes of primary spontaneous pneumothorax: a multicenter, prospective, randomized pilot study. Am J Respir Crit Care Med 2002;165:1240-4.

5. Kaneda H, Nakano T, Taniguchi Y, et al. Three-step management of pneumothorax: time for a re-think on initial management. Interact Cardiovasc Thorac Surg 2013;16:186-92.

6. Nishiuma T, Ohnishi H, Katsurada N, et al. Evaluation of simple aspiration therapy in the initial treatment for primary spontaneous pneumothorax. Intern Med 2012;51:1329-33.

7. Ramouz A, Lashkari MH, Fakour S, et al. Randomized controlled trial on the comparison of chest tube drainage and needle aspiration in the treatment of primary spontaneous pneumothorax. PakJ Med Sci 2018;34:1369-74.

8. Kim IH, Kang DK, Min HK, et al. A Prospective Randomized Trial Comparing Manual Needle Aspiration to Closed Thoracostomy as an Initial Treatment for the First Episode of Primary Spontaneous Pneumothorax. Korean J Thorac Cardiovasc Surg 2019;52:85-90. 
9. Thelle A, Gjerdevik M, SueChu M, et al. Randomised comparison of needle aspiration and chest tube drainage in spontaneous pneumothorax. Eur Respir J 2017;49:1601296.

10. Andrivet P, Djedaini K, Teboul JL, et al. Spontaneous pneumothorax. Comparison of thoracic drainage vs immediate or delayed needle aspiration. Chest 1995;108:335-9.

11. Oh SW, Hyun SY, Yang HJ, et al. Comparison of Simple Manual Aspiration and Chest Tube Drainage in the First Occurrence of a Primary Spontaneous Pneumothorax. J Korean Soc Emerg Med 2003;14:403-8.

12. Ho KK, Ong ME, Koh MS, et al. A randomized controlled trial comparing minichest tube and needle aspiration in outpatient management of primary spontaneous pneumothorax. Am J Emerg Med 2011;29:1152-7.

13. Ayed AK, Chandrasekaran C, Sukumar M. Aspiration versus tube drainage in primary spontaneous pneumothorax: a randomised study. Eur Respir J 2006;27:477-82.

14. Harvey J, Prescott RJ. Simple aspiration versus intercostal tube drainage for spontaneous pneumothorax in patients with normal lungs. British Thoracic Society Research Committee. BMJ 1994;309:1338-9.

15. Masood I, Ahmad Z, Pandey DK, et al. Role of simple needle aspiration in the management of spontaneous pneumothorax. J Assoc Physicians India 2007;55:628-9.

16. Mummadi SR, de Longpre' J, Hahn PY. Comparative Effectiveness of Interventions in Initial Management of Spontaneous Pneumothorax: A Systematic Review and a Bayesian Network Meta-analysis. Ann Emerg Med 2020;76:88-102.

17. Stradling P, Poole G. Conservative management of spontaneous pneumothorax. Thorax 1966;21:145-9.

18. Filosso PL, Guerrera F, Sandri A, et al. Errors and Complications in Chest Tube Placement. Thorac Surg Clin 2017;27:57-67.

19. Bailey RC. Complications of tube thoracostomy in trauma. J Accid Emerg Med 2000;17:111-4.

20. Rahman NM, Pepperell J, Rehal S, et al. Effect of Opioids vs NSAIDs and Larger vs Smaller Chest Tube Size on Pain Control and Pleurodesis Efficacy Among Patients With Malignant Pleural Effusion: The TIME1 Randomized Clinical Trial. JAMA 2015;314:2641-53.

21. Brown SGA, Ball EL, Perrin K, et al. Conservative versus Interventional Treatment for Spontaneous Pneumothorax. N Engl J Med 2020;382:405-15.

22. Hallifax RJ, McKeown E, Sivakumar P, et al. Ambulatory management of primary spontaneous pneumothorax: an open-label, randomised controlled trial. Lancet 2020;396:39-49.

23. Parlak M, Uil SM, van den Berg JW. A prospective, randomised trial of pneumothorax therapy: manual aspiration versus conventional chest tube drainage. Respir Med 2012;106:1600-5.

24. Röggla M, Wagner A, Brunner C, et al. The management of pneumothorax with the thoracic vent versus conventional intercostal tube drainage. Wien Klin Wochenschr 1996;108:330-3.

25. Sano A, Yotsumoto T, Tsuchiya T. Outpatient drainage for patients with spontaneous pneumothorax over 50 years of age. Lung India 2017;34:232-5.

26. Tsuchiya T, Sano A. Outpatient Treatment of Pneumothorax with a Thoracic Vent: Economic Benefit. Respiration 2015;90:33-9.

27. Kim YP, Haam SJ, Lee S, et al. Effectiveness of Ambulatory Tru-Close Thoracic Vent for the Outpatient Management of Pneumothorax: A Prospective Pilot Study. Korean J Radiol 2017;18:519-25.

28. Khan F, Vali Y, Naeem M, et al. Safety and efficacy of ambulatory management of secondary spontaneous pneumothorax: a case series. BMJ Open Respir Res 2019;6:e000373.

29. Saito H, Fukushima R, Kobori O, et al. Marked and prolonged depression of factor XIII after esophageal resection. Surg Today 1992;22:201-6.

30. Saeki H, Masuda T, Okada S, et al. Impact of perioperative peripheral blood values on postoperative complications after esophageal surgery. Surg Today 2010;40:626-31.

31. Homma T, Ojima T, Yamamoto Y, et al. Utility of the sliding lung sign for the prediction of preoperative intrathoracic adhesions. J Thorac Dis 2020;12:4224-32.

32. Lichtenstein DA, Menu Y. A bedside ultrasound sign ruling out pneumothorax in the critically ill. Lung sliding. Chest 1995;108:1345-8.

33. Baumann MH, Strange C, Heffner JE, et al. Management of spontaneous pneumothorax: an American College of Chest Physicians Delphi consensus statement. Chest 2001;119:590-602.

34. Light RW. Management of spontaneous pneumothorax. Am Rev Respir Dis 1993;148:245-8.

35. Salazar AJ, Aguirre DA, Ocampo J, et al. Evaluation of three pneumothorax size quantification methods on digitized chest $\mathrm{X}$-ray films using medical-grade grayscale and consumer-grade color displays. J Digit Imaging 2014;27:280-6. 
36. Melton LJ 3rd, Hepper NG, Offord KP. Incidence of spontaneous pneumothorax in Olmsted County, Minnesota: 1950 to 1974. Am Rev Respir Dis 1979; 120:1379-82.

37. Gupta D, Hansell A, Nichols T, et al. Epidemiology of pneumothorax in England. Thorax 2000;55:666-71.

38. Hallifax RJ, Goldacre R, Landray MJ, et al. Trends in the Incidence and Recurrence of Inpatient-Treated Spontaneous Pneumothorax, 1968-2016. JAMA 2018;320:1471-80.

39. Bobbio A, Dechartres A, Bouam S, et al. Epidemiology of spontaneous pneumothorax: gender-related differences. Thorax 2015;70:653-8.

40. Mummadi SR, Stoller JK, Lopez R, et al. Epidemiology of Adult Pleural Disease in the United States. Chest 2021;160:1534-51.

41. O'Hara VS. Spontaneous pneumothorax. Mil Med 1978;143:32-5.

42. Garraud O, Hozzein WN, Badr G. Wound healing: time to look for intelligent, 'natural' immunological approaches? BMC Immunol 2017;18:23.

43. Tanaka F, Itoh M, Esaki H, et al. Secondary spontaneous pneumothorax. Ann Thorac Surg 1993;55:372-6.

44. Seremetis MG. The management of spontaneous pneumothorax. Chest 1970;57:65-8.

45. Lassila R. Clinical Use of Factor XIII Concentrates. Semin Thromb Hemost 2016;42:440-4.

46. Watanabe N, Yokoyama Y, Ebata T, et al. Clinical influence of preoperative factor XIII activity in patients undergoing pancreatoduodenectomy. HPB (Oxford) 2017;19:972-7.

Cite this article as: Homma T, Ojima T, Shimada Y, Tanabe K, Yamamoto Y, Akemoto Y, Kitamura N. Effectiveness and failure factors of manual aspiration using a small needle for large pneumothorax in stable patients. J Thorac Dis 2022;14(2):321332. doi: $10.21037 /$ jtd-21-1587
47. Murata A, Kouno A, Yamamoto K, et al. The treatment of refractory pneumothorax in diffuse panbronchiolitis by intravenous administration of coagulation factor XIII concentrate. J Nippon Med Sch 2006;73:89-92.

48. Inoue $\mathrm{H}$, Nishiyama $\mathrm{N}$, Mizuguchi S, et al. Clinical value of exogenous factor XIII for prolonged air leak following pulmonary lobectomy: a case control study. BMC Surg 2014;14:109.

49. Takeda Y, Mise Y, Ishizuka N, et al. Effect of early administration of coagulation factor XIII on fistula after pancreatic surgery: the FIPS randomized controlled trial. Langenbecks Arch Surg 2018;403:933-40.

50. Zwischenberger JB, Bowers RM, Pickens GJ. Tension pneumothorax during extracorporeal membrane oxygenation. Ann Thorac Surg 1989;47:868-71.

51. Chinet AE. Chest-lung statics: a realistic analog for student laboratory. Am J Physiol 1989;257:S9-10.

52. Tanizaki S, Maeda S, Sera M, et al. Small tube thoracostomy (20-22 Fr) in emergent management of chest trauma. Injury 2017;48:1884-7.

53. Korczyński P, Górska K, Nasiłowski J, et al. Comparison of Small Bore Catheter Aspiration and Chest Tube Drainage in the Management of Spontaneous Pneumothorax. Adv Exp Med Biol 2015;866:15-23.

54. Miller WC, Toon R, Palat H, et al. Experimental pulmonary edema following re-expansion of pneumothorax. Am Rev Respir Dis 1973;108:654-6.

55. Haga T, Kurihara M, Kataoka H. Risk for re-expansion pulmonary edema following spontaneous pneumothorax. Surg Today 2014;44:1823-7. 